\title{
O ENSINO DA GRAMÁTICA NO PROCESSO DE AQUISIÇÃO DA LINGUAGEM
}

\section{Cíntia Maria Basso}

\section{CONSIDERAÇÕES INICIAIS}

O ensino da Língua Portuguesa remete-nos a uma reflexão sobre a linguagem. Esta é resultante da interação entre o homem e a realidade social em que o mesmo está inserido. É uma mediação necessária, constituindo-se em ações que se transformam e se modificam. Como afirma Orlandi,

(...) a linguagem, então, entendida como mediação necessária, não é instrumento, mas é ação que transforma (...) na perspectiva do discurso, a linguagem não aparece apenas como instrumento de comunicação ou transmissão de informação, ou suporte de pensamento, mas como lugar de conflito, de confronto ideológico, e em que a significação se apresenta em toda sua complexidade. (1996, p.82-83)

Sendo a linguagem resultado da interação sócio-histórico-cultural, ela deve ser entendida como um todo e presa a regras fixas. No entanto, através do uso que os interlocutores fazem dela no processo de interação, ela poderá ser flexível e mutável. É, portanto, por meio do ensino da gramática acoplado a atividades de ensino comunicativo, que o aluno terá sucesso em seu desempenho lingüístico no processo de aquisição da linguagem.

\section{ENSINO COMUNICATIVO E ENSINO DA GRAMÁTICA - PRÁTICAS QUE SE INTERLIGAM NO PROCESSO DE AQUISIÇÃO DA LINGUAGEM}

No desenvolvimento lingüístico da criança existem três fases. Segundo Wells (1989), na primeira e na segunda fases ocorre a interrelação entre a linguagem, ação e contexto social, ou seja, a linguagem em seu contexto de atividade prática. A primeira fase é de regulação. Nessa fase, a linguagem funciona como um meio que regula a atividade e a interação e sua função é representar os objetos e as ações que formam sua experiência. Assim, ocorre a ampliação da capacidade de simbolizar e os sons têm significado e propósito nas atividades repetitivas.

A segunda fase é de socialização, ou seja, da consolidação e da diversificação. Através da participação na conversa com outros, a criança descobre, simultaneamente, a sua identidade, assumindo a linguagem de sua comunidade e absorvendo os valores culturais. É a fase em que a criança ganha controle da variedade de registros de diferentes linguagens.

A terceira fase é da internalização. A criança se conscientiza de seu estado mental e é capaz de refletir sobre sua experiência, ou seja, ela reflete internamente a partir do processo de escolarização. Nessa fase, a função que a linguagem executa de representar os objetos e as experiências é utilizada para fornecer um meio para comunicar para outros o processo de pensamento. A 
criança começa a adquirir sua própria interpretação de experiências para chegar a influenciar as interpretações dos outros.

Ellis (1997) acredita na importância do ensino da gramática no processo de aquisição da linguagem. Segundo este autor, isso não quer dizer que o aluno precise decorar regras gramaticais, mas sim focalizar a forma, ou seja, distanciarse do significado e analisar como a expressão utilizada veicula esse significado. Desta forma, no ensino de línguas é preciso reunir atividades comunicativas e de ensino da gramática. Segundo Ellis apud Richter (2000. Não paginado), "(...) alunos que recebem instrução gramatical ultrapassam os que não a recebem, tanto em termos de velocidade de aquisição quanto em termos de nível de competência atingido".

Algumas características do ensino comunicativo de línguas são apresentadas por Richter:

- os erros são corrigidos, porém em número limitado;

- o uso e o significado prevalecem sobre a forma;

- o material lingüístico empregado nas aulas é tornado compreensível através de pistas do contexto, gestos, imagens, etc. e não por progressão estrutural;

- $\quad$ os tipos de discurso são em número relativamente amplo;

- o fundamental é compreender e ser compreendido, o resto decorre disso;

- há pressão para produção, mas sem pressão por correção;

- o input modificado, isto é, a simplificação da linguagem, é usado para melhorar a comunicação entre todos, quando necessário;

- o tempo para praticar é limitado, exceto nas estratégias interdisciplinares quando a língua-alvo é usada para auxiliar ou realizar o estudo de outras matérias ou tópicos do currículo. (2000, p.75-76)

\section{O ENSINO NA PERSPECTIVA DA PEDAGOGIA DE PROJETOS}

De acordo com Ellis (1997), os traços frágeis deveriam ser atacados através da gramática reflexiva, ou seja, através de oficinas e ensino através da Pedagogia de Projetos. Segundo Richter, a Pedagogia de Projetos

(...) consiste em uma investigação-ação cuja ação social transformadora a realizar é (essencialmente) uma ação comunicativa. Esta pode se corporificar em diferentes linguagens e veículos; mas pretende operar alguma modificação no ambiente social abrangido pelo veículo da comunicação (...) é um ensino-baseado-em-tarefas (...) é um ensino centrado no aluno, processual em termos de todos os parâmetros de curso (...) a aquisição da linguagem se dá em bases interacionistas. (Não paginado)

Assim, o ensino da gramática pode ser trabalhado com bastante eficácia em um ensino baseado na Pedagogia de Projetos, ou seja, através de uma sucessão organizada de tarefas. É por meio de textos, lidos ou produzidos, que os alunos aprenderão o sentido das palavras e a relação entre elas. Organizando o texto, o aluno terá a possibilidade de expressar sua visão de mundo. Uma das estratégias utilizadas na produção textual pode ser a formulação de paráfrases (as diferentes maneiras de dizer a mesma coisa). Segundo Richter (1999), as formulações de paráfrases estimulam a aquisição e contribuem para a proficiência. Elas 
(...) são extremamente úteis, por um lado, para trabalhar as diferentes nuances que uma idéia pode apresentar em função de suas múltiplas e possíveis formulações e, por outro lado, para ajudar a compreender bem determinadas noções complexas: se o aluno decora um conteúdo ou simplesmente copia um texto para "responder" a uma questão, não "reagiu" verdadeiramente ao conteúdo e não se pode dizer que o assimilou; no entanto, esforçando-se para parafrasear o que estuda, ou seja, dizer com outras palavras o que lê ou ouve, converte o material percebido em estruturas pertencentes ao conhecimento armazenado - quando consegue explicar o que entendeu com suas palavras, o aluno mostra, também, que entendeu. $E$ pode empregar esse conhecimento pré-construído, que agora é "seu", para gerar novos conhecimentos. (p.82)

Os Parâmetros Curriculares Nacionais da Língua Portuguesa (PCNs) também consideram um ensino através de projetos. Segundo os autores,

os projetos são excelentes situações para que os alunos produzam textos de forma contextualizada - além do que, dependendo de como se organizam, exigem leitura, escuta de leituras, produção de textos orais, estudo, pesquisa e outras atividades. (...) Os projetos, além de oferecerem reais condições de produção de textos escritos, carregam exigências de grande valor pedagógico:

- podem apontar a necessidade de ler e analisar uma grande variedade de textos e portadores do tipo que se vai produzir: como se organizam, que características possuem ou quais têm mais qualidade. (...);

- $\quad$ o exercício de o escritor ajustar o texto à imagem que faz do leitor fisicamente ausente permite que o aluno aprenda a produzir textos escritos mais completos, com características de textos escritos mesmo. (...);

- (...) a necessidade de revisão e cuidado com o trabalho se impõe, pois a legibilidade passa a ser um objetivo deles (...);

- (...) é possível uma intersecção entre conteúdos de diferentes áreas (...);

- (...) favorecem o necessário compromisso do aluno com sua própria aprendizagem. (PCNs, 1997, p.70-73)

\section{O ENSINO DA GRAMÁTICA E SEUS BENEFÍCIOS NA AQUISIÇÃO DA LINGUAGEM}

Richter afirma que o ensino da gramática traz diversos benefícios ao aluno. Segundo ele,

sabe-se hoje que o ensino da gramática beneficia especialmente a produção planejada, apresentando pouco efeito na produção espontânea do aluno. Isto significa que a gramática contribui decisivamente para o aluno escrever melhor, embora apresente influência pequena na expressão oral deste. (...) o sucesso do ensino da gramática parece estar estreitamente relacionado ao estágio de desenvolvimento lingüístico em que o aluno se encontra. (2000, p.18-19)

Portanto, o ensino da gramática deve seguir a seqüência natural de aquisição. Não adianta ensinar algo muito complexo para uma criança que ainda não está suficientemente "madura" para entender, isto é, é necessário acompanhar os alunos dentro da rota do português escrito. Nessa etapa, o input (agir sobre uma mensagem para verificar o que entendeu sobre determinado assunto) poderá ser mais sofisticado, porém, o output (através da negociação de sentidos, o aluno poderá produzir uma nova mensagem sobre o que realmente entendeu) não 
poderá ser muito exigido do aluno.

Entende-se por aquisição da linguagem a internalização de formas, regras, determinados mecanismos sintáticos de tal maneira que os falantes consigam produzir algo de maneira fluente como, por exemplo, fazer automaticamente uma tarefa de leitura e produção de textos. Uma regra ou habilidade comunicativa está adquirida quando o aluno faz uso dela instintivamente.

Portanto, a eficácia no ensino da gramática depende de uma prática lingüística constante ao longo da vida, com boas práticas dos professores de línguas. Esses devem ensinar a gramática com feedback e assistência, tendo o cuidado quando vão escolher como, quando e com que objetivos focalizar a forma, ou seja, deveriam focalizar com mais intensidade o que o aluno apresenta de mais problemático no momento. O ensino da gramática oferece mais resultados quando o nível de desenvolvimento em que o aluno está é compatível com as formas que estão sendo trabalhadas. Assim o aluno poderá assimilar os itens lingüísticos que estão sendo ensinados, por exemplo, por meio da Investigação-Ação Educacional em sala de aula.

\section{O PROFESSOR E SUA PRÁTICA PEDAGÓGICA NO ENSINO DE LÍNGUAS}

Dentre os elementos gramaticais que cabem ao professor ensinar, Ellis apud Richter (2000) nos aponta critérios de preferência para selecioná-los:

- atacar os traços frágeis (estes não podem ser aprendidos antes da hora, o aluno não consegue se dar conta porque são mais complexos) antes dos resilienses (são adquiridos de forma natural, através da comunicação);

- $\quad$ os traços redundantes (por exemplo: plural; masculino/feminino) devem predominar sobre os não-redundantes;

- $\quad$ os traços mais marcados (têm um comportamento mais específico) devem predominar sobre os menos marcados (não-redundantes);

- deve-se destacar as estruturas mais marcadas. (Não paginado)

O professor pode empregar técnicas, como elicitação do desempenho do aluno e mecanismo de feedback. No primeiro caso, o professor propõe tarefas que levem o aluno a ter um melhor desempenho. Nesse caso, o que o professor quer é que o aluno crie determinadas estruturas para verificar em que nível está a interlíngua do mesmo, ou seja, o perfil de domínio das regras gramaticais. No segundo caso, mecanismos de feedback, o professor procura fazer o aluno refletir sobre o que ele já produziu. Estes mecanismos vão fornecer um "relato" sobre o que o aluno está conseguindo aprender e o que ainda não conseguiu. (Ellis apud Richter, 2000, não paginado)

A elicitação do desempenho do aluno se subdivide em comunicação focalizada e foco na marca formal. A comunicação focalizada é uma estratégia em que predispomos o aluno a interagir utilizando os itens gramaticais que nos interessa. O foco em marca formal é uma tentativa de se distanciar do conteúdo e trabalhar em cima de formas de expressão. Existem duas maneiras de fazer isso: através da via dedutiva (vai do geral para o particular, ensino dedutivo) e da via indutiva (vai do particular para o geral, implica trabalhar casos até chegar a regra). 0 
professor deverá decidir, de acordo com o nível de desenvolvimento dos alunos, quando usar a via dedutiva e quando usar a via indutiva. (Ellis apud Richter, 2000, não paginado)

O saber fazer, ou seja, o conhecimento prático, tem orientação ao output e ao input. O saber fazer orientado ao output se dá duas maneiras: evitação do erro e indução ao erro. No primeiro caso, lança-se o aluno a assumir riscos comunicando-se a vontade. $O$ professor utiliza atividades que direcionam o aluno a ser correto desde o início, através da manipulação de textos ou criação de textos. No segundo caso, a estratégia de indução ao erro, o aluno expressa-se e, quando erra, o professor apenas registra esse erro para focalizá-lo em outro momento. (Ellis apud Richter, 2000, não paginado)

De acordo com Ellis apud Richter (2000), o conhecimento prático com orientação ao input acontece de duas maneiras: insumo intensivo e enriquecimento de insumo. No insumo intensivo o professor oferece uma carga enorme de material lido e/ou ouvido. Utilizando o insumo intensivo o professor consegue fazer com que o aluno aprenda novas estruturas e novas formas de expressão, mas não serve para erradicar estruturas incorretas já existentes, para isso é preciso aplicar instruções explícitas sobre as produções dos alunos.

O input deve ser compreensivo, ocasionando a assimilação do conteúdo pelo aluno e não apenas a famosa "decoreba" das regras da língua. O input se torna compreensível desde que se leve em conta também, segundo Richter (2000)

- $\quad$ o aproveitamento das pistas fornecidas pelo contexto e pelo conhecimento prévio do aluno;

- $\quad$ o ajuste da interação, ou seja, a atitude cooperativa no diálogo, permitindo que o aprendiz consiga transmitir o que quer e considera importante. (p.47)

Estratégias de modificação ocorrem no enriquecimento de insumo de textos para que os alunos incorporem vários traços lingüísticos. Esta estratégia é eficaz para ensinar alguns tipos de estruturas sintáticas complexas. Quando o input (material fornecido) sofre modificações pode ser na estrutura e em adaptações. Existem dois tipos de feedback: explícito e implícito. No feedback explícito o professor deixa claro ao aluno o que ele fez de errado para que ele trabalhe em cima de seus erros. Existem três tipos de feedback explícito: metalingüístico (estratégias de metacognição), baseado na repetição (do enunciado do aluno, com tom de questionamento) e foco no erro como um recurso lingüístico. No feedback implícito o professor oferece uma réplica ao aluno, procurando fazer com que ele pense e reflita sobre o que fez de errado. Tanto o feedback implícito como o explícito ocasionam uma melhora no aprendizado. Os alunos precisam ser incentivados a trabalhar com diversos gêneros e serem forçados a produzirem vários textos. (Ellis apud Richter, 2000)

\section{O CONHECIMENTO NO ENSINO DE LÍNGUAS}

Dois tipos de conhecimento são trabalhados no ensino de línguas, segundo Ellis apud Richter (2000): o conhecimento implícito e o conhecimento explícito. O 
conhecimento implícito é intuitivo; resulta do aprendizado incidental; manifesta-se no desempenho lingüístico, no uso; aparece indiretamente; é procedimental, isto é, não tem a ver com regras, mas sim com procedimentos. Este conhecimento pode ser subdividido em: controlado (a regra, para ser utilizada, precisa da atenção do falante para monitorar etapas que estão envolvidas no processo) e automático (o falante utiliza a regra de maneira automatizada, ou seja, quando ocorreu aquisição por parte do aluno).

O conhecimento explícito é analítico; distancia-se do significado e aplica uma metacognição sobre a forma; é abstrato; procura estabelecer generalizações; é um conhecimento explanatório, estruturado; sempre é consciente, mas pode ser internalizado e se tornar não consciente. Este conhecimento pode ser controlado (consiste em mobilizar a regra - fluência e eficiência); pode ser automático, prático; supõe metaconhecimento das regras e pode ser desenvolvido através de atividades de memorização ou resolução de problemas. (Ellis apud Richter, 2000)

Conforme Ellis apud Richter (2000), o aluno é capaz de extrapolar os conhecimentos que o professor trabalha em sala de aula. Parte da competência lingüística do aluno na escola é em decorrência do ensinamento implícito. Para que o input seja transformado em conhecimento implícito é preciso que o aluno: discrimine (prestar atenção à elementos específicos do input); compare (contrastar esses elementos discriminados com os elementos análogos que o aluno produz em sua comunicação) e integre (o aluno constrói novas hipóteses sobre a língua tais que permitam que ele incorpore os elementos que foram discriminados e comparados no seu sistema de interlíngua, o qual transforma-se em conhecimento adquirido ao aluno).

Para Richter,

o processamento lingüístico maduro envolve tanto as estratégias top-down (de conhecimento de mundo) quanto as bottom-up (de "injeção" de dados), cujo peso no processo depende, em parte, da natureza cognitiva da tarefa. (...) Não é a compreensão que leva ao aprendizado, e sim seu oposto, a não-compreensão. A facilidade com que uma tarefa de compreensão é executada pode estar escondendo falta de progresso na esfera gramatical. Quanto a este aspecto, vale lembrar a máxima de Vygotsky: o aprendizado é que "puxa" o desenvolvimento. (...) a condição (...) para o ensino bem-sucedido é a ampliação constante da zona de desenvolvimento proximal do aprendiz. (2000, não paginado)

A Zona de Desenvolvimento Proximal é a distância entre o Nível de Desenvolvimento Real do aluno (o que ele consegue fazer com a ajuda de outros) e o Nível de Desenvolvimento Potencial (o que ele pode realizar com a ajuda de alguém mais capaz no momento).

\section{CONSIDERAÇÕES FINAIS}

Portanto, torna-se necessário a existência de um currículo centrado no aluno. Elaborar este currículo equivale a tomar uma série de decisões, como

- $\quad$ identificação das necessidades e expectativas dos estudantes; 
- estabelecimento de metas e objetivos;

- $\quad$ seleção e graduação de itens de conteúdo programático;

- critérios de distribuição de alunos em classes;

- $\quad$ seleção, adaptação e/ou elaboração de materiais e atividades de ensino;

- elaboração de instrumentos de avaliação. (Richter, 2000, p.94)

Segundo o referido autor, existem dois caminhos para percorrer estas decisões,

um, o mais tradicional (...) é simplesmente prescrever os parâmetros curriculares. Quem faz isso é o professor ou mesmo a instituição, com base num modelo de meios-fins no qual o conteúdo programático gira em torno de itens gramaticais. (...) $O$ outro caminho é negociar os parâmetros curriculares. Estes passam a ser definidos em função do esforço colaborativo de professores e alunos. Este currículo, centrado no aluno, (...) é elaborado em boa parte no seu transcorrer (...) selecionam-se e graduam-se atividades que reflitam o que o estudante estipula que pretende utilizar na vida real ou num momento subseqüente de sua formação (...) os objetivos consistem não somente em obter do aluno um perfil de habilidades lingüísticas (...) mas também em desenvolver no educando a habilidade de aprender, ou seja, de assimilar e aplicar estratégias de produção crítica de conhecimento. (Richter, 2000, p.94-95)

Desta forma, para ensinar a língua é preciso criar situações que permitam ao aluno refletir sobre a linguagem nos seus variados contextos de uso, isto é, através da leitura e produção de textos, enfocados não apenas no ensino comunicativo, mas também, no ensino da gramática. Através dessa prática, os alunos irão analisar criticamente a produção de seus próprios materiais, trabalhando com as múltiplas linguagens, para que possam, de fato, utilizar essa variedade em seus textos. O essencial no ensino de línguas é ler analisando os recursos lingüísticos de cada texto, interpretar, compreender, refletir e produzir diferentes tipos de textos constantemente. Isso é possível através da elaboração de projetos, nos quais o aluno escreva para interlocutores reais, divulgando de alguma forma os resultados alcançados por meio desses projetos.

\section{BIBLIOGRAFIA}

BEHARES, Luis E. Aquisição da linguagem e a questão do ensino. SEMINÁRIO INTERNACIONAL DE ALFABETIZAÇÃO \& EDUCAÇÃO CIENTÍFICA. Anais: II Seminário Internacional de Alfabetização \& Educação Científica. Ijuí: Ed. da UNIJUÍ, 1994. p.5-19.

BRASIL. Secretaria de Educação Fundamental. Parâmetros Curriculares Nacionais: Introdução. Brasília: MEC/SEF, 1997. V.1.

BRASIL. Secretaria de Educação Fundamental. Parâmetros Curriculares Nacionais: Língua Portuguesa. Brasília: MEC/SEF, 1997. V.2.

ELLIS, Rod. SLA research and language teaching. Oxford, Oxford University Press, 1997. Capítulos 1 a 6.

SMOLKA, Ana Luísa \& GÓES, Maria Cecília (Orgs.). A linguagem e o outro no espaço escolar: Vygotsky e a construção do conhecimento. 4.ed.

Campinas, SP : Papirus, 1995.

OLIVEIRA, Marta Kohl. O pensamento e a linguagem na perspectiva sóciohistórica. SEMINÁRIO INTERNACIONAL DE ALFABETIZAÇÃO \& EDUCAÇÃO CIENTÍFICA. Anais: I Seminário Internacional de Alfabetização \& Educação 
Científica. Ijuí : UNIJUÍ, 1993. p. 19-33.

ORLANDI, Eni Pulcinelli. A linguagem e seu funcionamento: as formas do discurso. 4.ed. Campinas: Pontes, 1996.

RICHTER, Marcos Gustavo. Aquisição da linguagem e ensino. Santa Maria: UFSM, 2000. Não paginado. Digitado.

RICHTER, Marcos Gustavo. Ensino do Português e interatividade. Santa Maria: Ed. da UFSM, 2000.

RICHTER, Marcos Gustavo. Focalizando a gramática na pedagogia de projeto.

BEVILAQUA, Ceres et al. Leitura e produção de textos. Santa Maria: Ed. da UFSM, 1999. p.81-87.

RICHTER, Marcos Gustavo. Pedagogia de projeto no ensino do português. Santa Maria: UFSM. Não paginado. Digitado.

SILVA, Josenia Vieira da. A aquisição da linguagem e o ensino da língua materna. Revista Internacional de Língua Portuguesa, n.11, p.56-60, 1994.

SMOLKA, Ana Luiza B. et. alii. Leitura e desenvolvimento da linguagem. Porto Alegre: Mercado Aberto, 1989.

WELLS, Gordon. Language, literacy and education. In: WELLS, Gordon et. alii. Learning through interactive: the study of language development. C.U.P., 1989. 